$\mathrm{CCH}$ has been issuing advance bulletins for the ACLP since October 1980. At the time of writing (1 October 1981) ten such bulletins had been published keeping the subscriber up-to-date.

One can subscribe to the Australian Company Law Library, which includes Australian Company Law \& Practice and Australian Company Law Cases.

Further information about these services may be obtained from: CCH Australia Ltd., P.O. Box 230, North Ryde, NSW, Australia, 2113, or from any office of Commerce Clearing House, Inc.

\title{
THAILAND BUSINESS LAW
}

A variety of materials in English are published about the legal aspects of business in Southeast Asia. One of the latest works of this kind is the Thailand Business Legal Handbook. The 68-page publication is available from:

International Legal Counsellors Thailand Ltd.

Southeast Insurance Building

315 Silom Road

8th Floor

Bangkok 5

Thailand US \$5.

The price is US $\$ 10$, and there is an additional mailing charge of

\section{AFRICAN LAW BIBLIOGRAPHY}

In 1972 Professor Jacques Vanderlinden, a well-known African law specialist and currently Professor of African Law at the Free University of Brussels, published the African Law Bibliography 1947-1966. Praised by the reviewers for its detail and range of scope, the work became immediately recognized as the most comprehensive guide to the literature on African law for the period of its coverage.

Professor Vanderlinden is now announcing the publication of two further volumes in the bibliographic series. African Law Bibliography 1967-1976 is expected to come out in the latter part of 1981; African Law Bibliography 1977-1980 is already available. Work is also progressing on the compilation of an annual supplement for 1981 as the first installment in a continuing series of such supplements.

Following the scope of the original work, the two new volumes, as well as the annual supplements, will offer bibliographic information not only about books on the law and legal systems of more than fifty African 